\title{
Corrigendum
}

\section{Flour fortification with iron has no impact on anaemia in urban Brazilian children - Corrigendum}

Maria CF Assunção, Iná S Santos, Aluísio JD Barros, Denise P Gigante and Cesar G Victora

First published online 9 August 2012

doi:10.1017/S1368980012003047, Published online by Cambridge University Press 15 Jun 2012

In the title of Table 4, instead of:

Table 4 Daily intake of iron per child $\left(n 744^{*}\right)$. Pelotas, Southern Brazil, 2008

it should read:

Table 4 Daily intake of iron per child $\left(n 774^{*}\right)$. Pelotas, Southern Brazil, 2008

\section{Reference}

Assunção MCF, Santos IS, Barros AJD, Gigante DP \& Victora CG (2012) Flour fortification with iron has no impact on anaemia in urban Brazilian children. Public Health Nutrition, published online 15 June 2012, doi:10.1017/S1368980012003047. 